\title{
A STAND-ALONE INDUCTION GENERATOR WITH IMPROVED STATOR FLUX ORIENTED CONTROL
}

\author{
Dinko Vukadinović — Mateo Bašić *
}

\begin{abstract}
This paper presents an improved stator flux oriented (SFO) control system for a stand-alone induction generator. The induction generator supplies a variable resistive dc load. In order to provide an essentially constant terminal voltage, the product of the rotor speed and the stator flux reference should remain constant. However, in this case the control system is not able to function properly at different loads and dc-link voltages. In this paper, we introduce a new algorithm in which this product is constant at certain dc-load and dc-link voltage references. The dependence of the stator flux reference on the dc load and dc voltage reference is mapped using an artificial neural network (ANN). We also present an analysis of the efficiency of the SFO control system, as well as its performance during transients, over a wide range of both dc-link voltage references and loads. The validity of the proposed approach is verified by realistic simulation in a Matlab-Simulink environment.
\end{abstract}

K e y w o r ds: automation, induction generator, neural networks, efficiency, stator field control

\section{INTRODUCTION}

Since the 1930s, it has been known that a three-phase induction machine can work as a self-excited induction generator (SEIG) $[1,2]$. Due to their simplicity, robustness, and small size per $\mathrm{kW}$ generated, induction generators are favoured for small hydroelectric and wind powered plants. One distinct advantage of the SEIG is its much lower unit cost compared with the conventional synchronous generator [3]. Recent widespread adaptation of power electronics and microcontrollers has enabled use of these generators with increased efficiency, for power generation of up to $500 \mathrm{~kW}$ when connected to the power grid. In contrast, the maximum power of a stand-alone SEIG does not go much beyond $15 \mathrm{~kW}$ [4].

In isolated applications, an induction generator operates with three AC capacitors connected to the stator terminals, or with a power converter and a single dc capacitor [5]. Once an induction generator is excited, the capacitor maintains the excitation. The minimum dc capacitance required for the initiation of voltage buildup can be found in reference [6]. For a given capacitance, self-excitation can only be achieved and maintained over certain load and speed ranges. Even when the capacitor is properly chosen, additional mechanisms must be added to avoid demagnetization and to achieve better control of the voltage produced. Some of these mechanisms include field-oriented techniques [7-11]. Contemporary research focuses on control mechanisms using stator flux orientation as well as those using rotor flux orientation.

This paper investigates a control system for an induction generator that uses the stator flux orientation. Systematic analysis of this control system is carried out for wide ranges of both load and speed. The induction generator supplies a variable dc load. To provide an essen- tially constant terminal voltage, the product of the rotor speed and the stator flux should remain constant. In the recent literature, this product is constant over the operating range of the generator. In this paper, we introduce a new algorithm in which this product is constant at certain dc-load and dc-link voltage references. Complex variables (phasors) are denoted by bold font Latin: $\boldsymbol{u}, \boldsymbol{i}$ and Greek: $\psi$, respectively.

Since this paper focuses on modelling and behaviour of the electrical part of the system, the turbine is not taken into account. Rotor speed is taken as an independent and variable input into the model.

\section{Nomenclature}

E $\quad$ No load stator voltage

$i_{d c} \quad$ Total dc current

$i_{\text {dec }} \quad$ Decoupling current

$u_{d c} \quad$ DC-link voltage

$\boldsymbol{i}_{s} \quad$ Space vector of the stator currents

$i_{r} \quad$ Space vector of the rotor currents

$i_{s a}, i_{s b}, i_{s c}$ Stator phase currents

$L_{s}, L_{r}, L_{m}$ Stator, rotor and mutual inductance

$p \quad$ Averaged dc-link power

$R_{s}, R_{r} \quad$ Stator and rotor resistance

$S_{a}, S_{b}, S_{c} \quad$ Switching functions of the three inverter legs

$s \quad$ Laplace operator

$T_{r} \quad$ Rotor time constant

$u_{s a}, u_{s b}, u_{s c}$ Stator phase voltages

$\boldsymbol{u}_{s} \quad$ Space vector of the stator voltages

$x \quad$ Magnetization factor

$\eta \quad$ Efficiency

$\sigma \quad$ Total leakage factor

$\psi_{s} \quad$ Space vector of the stator flux-linkages

$\boldsymbol{\psi}_{r} \quad$ Space vector of the rotor flux-linkages

* University of Split, Faculty of Electrical Engineering, Mechanical Engineering and Naval Architecture, R. Boškovića 32, 21000 Split, Croatia,dvukad@fesb.hr, mabasic@fesb.hr 


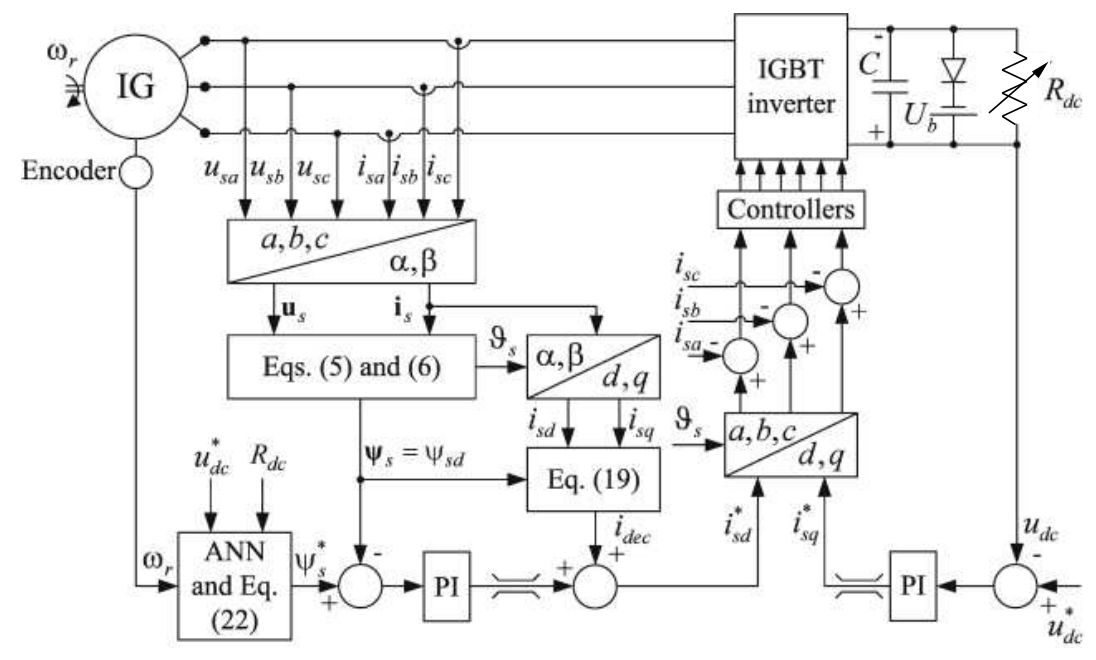

Fig. 1. SFO control system of an induction generator

$\begin{array}{ll}\omega_{a} & \text { Arbitrary angular speed } \\ \omega_{r} & \text { Rotor speed } \\ \omega_{e} & \text { Fundamental stator frequency } \\ \omega_{s} & \text { Slip frequency } \\ * & \text { Superscript for a reference variable } \\ i_{s d}, i_{s q}\left(i_{s \alpha}, i_{s \beta}\right) & \text { Stator currents expressed in the } d, q \\ & (\alpha, \beta) \text { reference frame } \\ u_{s d}, u_{s q}\left(u_{s \alpha}, u_{s \beta}\right) & \text { Stator voltages expressed in the } d, q \\ & (\alpha, \beta) \text { reference frame } \\ x_{\min }, x_{\max }, x_{\mathrm{avg}} & \text { Minimum, maximum and average } \\ & \text { magnetization factor } \\ \psi_{s d}, \psi_{s q}\left(\psi_{s \alpha}, \psi_{s \beta}\right) & \text { Stator flux-linkages expressed in the } \\ & d, q(\alpha, \beta) \text { reference frame }\end{array}$

\section{MODEL OF THE INDUCTION GENERATOR SYSTEM}

\subsection{Induction Generator Model and Stator Flux Estimation}

Figure 1 shows the SFO control system of an induction generator. The stator flux reference is determined by a neural network. The induction generator shown in Fig. 1 can be described by the following equations in a reference frame with arbitrary angular speed $\omega_{a}[12]$

$$
\begin{aligned}
\boldsymbol{u}_{s} & =\boldsymbol{i}_{s} R_{s}+\frac{\mathrm{d} \boldsymbol{\psi}_{s}}{\mathrm{~d} t}+j \omega_{a} \boldsymbol{\psi}_{s} \\
0 & =\mathbf{i}_{r} R_{r}+\frac{\mathrm{d} \boldsymbol{\psi}_{r}}{\mathrm{~d} t}+j\left(\omega_{a}-\omega_{r}\right) \boldsymbol{\psi}_{r} \\
\boldsymbol{\psi}_{s} & =L_{s} \mathbf{i}_{s}+L_{m} \boldsymbol{i}_{r} \\
\boldsymbol{\psi}_{r} & =L_{m} \mathbf{i}_{s}+L_{m} \mathbf{i}_{r}
\end{aligned}
$$

Equations (1) and (2) can be simplified by choosing the stationary reference frame $\left(\omega_{a}=0\right)$. By eliminating the rotor currents and rotor flux linkages from (2), we obtain the following equations, which include the stator currents and the rotor flux linkages as state variables

$$
\begin{aligned}
\frac{\mathrm{d} \psi_{s \alpha}}{\mathrm{d} t} & =u_{s \alpha}-R_{s} i_{s \alpha}, \\
\frac{\mathrm{d} \psi_{s \beta}}{\mathrm{d} t} & =u_{s \beta}-R_{s} i_{s \beta}, \\
\frac{\mathrm{d} i_{s \alpha}}{\mathrm{d} t} & =\frac{1}{L_{m}^{2}-L_{s} L_{r}}\left(R_{r} L_{s} i_{s \alpha}-R_{r} \psi_{s \alpha}\right. \\
& \left.-\left(L_{m}^{2}-L_{s} L_{r}\right) \omega_{r} i_{s \beta}-L_{r} \omega_{r} \psi_{s \beta}\right), \\
\frac{\mathrm{d} i_{s \beta}}{\mathrm{d} t} & =\frac{1}{L_{m}^{2}-L_{s} L_{r}}\left(R_{r} L_{s} i_{s \beta}-R_{r} \psi_{s \beta}\right. \\
& \left.-\left(L_{m}^{2}-L_{s} L_{r}\right) \omega_{r} i_{s \alpha}-L_{r} \omega_{r} \psi_{s \alpha}\right) .
\end{aligned}
$$

The magnetizing inductance as a function of the magnetizing current $\left(L_{m}=f\left(i_{m}\right)\right)$ is required in Eqs. (7) and (8). This is known, as it is calculated from the magnetization curve obtained from the traditional no-load test $[13,14]$.

Estimation of the stator flux is based upon Eqs. (5) and (6), which are affected only by stator resistance variation.

\subsection{Current Controlled Inverter Model, DC link and Load Model}

By considering a resistive load connected to the dc link and assuming the inverter as an ideal current source that transfers energy between the dc-link and the induction generator, the dc-link can be represented by the following equation

$$
u_{d c}=-\frac{1}{C} \int_{0}^{t}\left(i_{d c}+\frac{u_{d c}}{R_{d c}}\right)+u_{d c 0}
$$

where $C$ is the dc-link capacitance and $R_{d c}$ is the resistive load. The initial voltage on the capacitor is denoted by $u_{d c 0}$. 


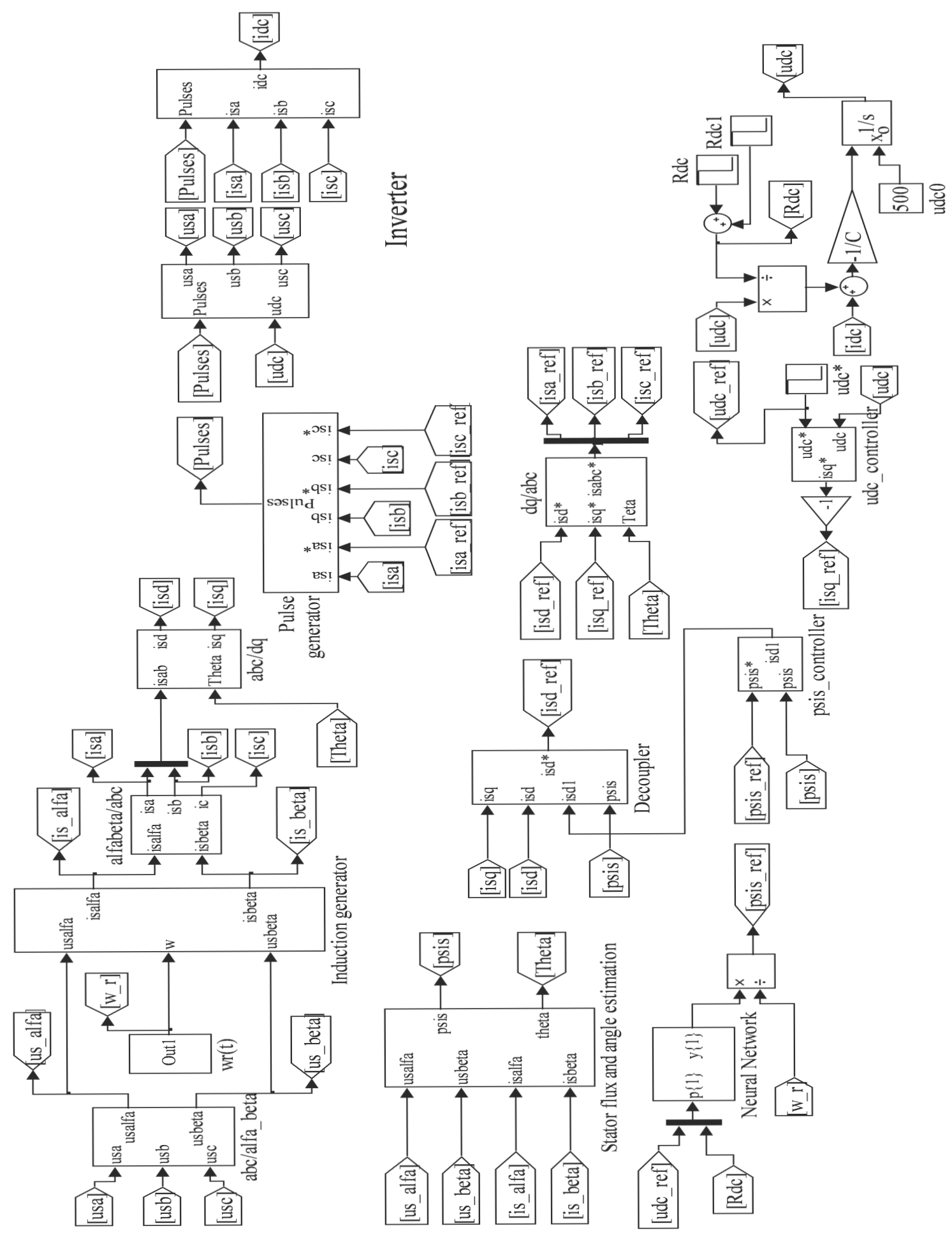

Fig. 2. Simulink model of the SFO control system of an induction generator

Stator phase voltages created by the inverter are expressed in terms of the switching functions as

$$
\begin{aligned}
& u_{s a}=\frac{1}{3} u_{d c}\left(2 S_{a}-S_{b}-S_{c}\right), \\
& u_{s b}=\frac{1}{3} u_{d c}\left(2 S_{b}-S_{c}-S_{a}\right), \\
& u_{s c}=\frac{1}{3} u_{d c}\left(2 S_{c}-S_{a}-S_{b}\right) .
\end{aligned}
$$

The total dc current $i_{d c}$ can be expressed using the inverter switching function as follows

$$
i_{d c}=S_{a} i_{s a}+S_{b} i_{s b}+S_{c} i_{s c} .
$$

The value of the switching function for any of the three inverter legs is determined by the hysteresis current con- 


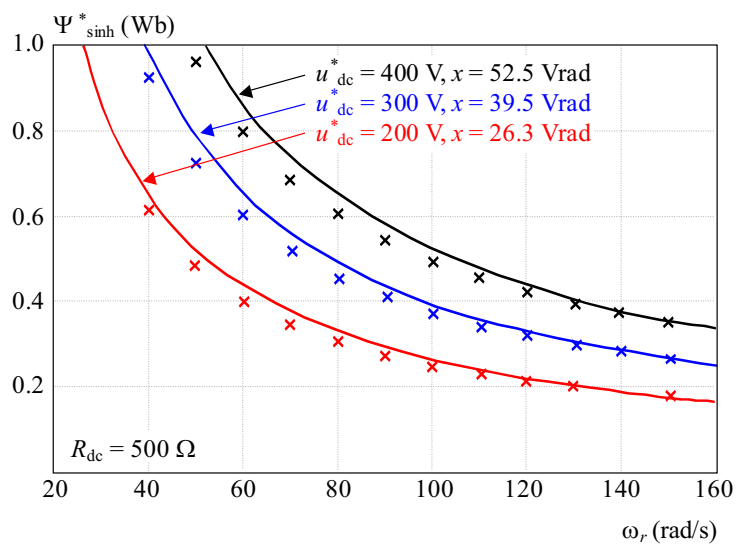

Fig. 3. Minimum stator flux reference versus rotor speed obtained at fixed load and varying dc-link voltage reference

troller of the given phase. In simulations, twice the hysteresis band equal to 0.1 is selected.

\subsection{Stator Flux Oriented Control System}

In order to model any field oriented control system, it is necessary to choose the synchronously rotating reference frame $(d, q)$. This means that the arbitrary angular speed $\omega_{a}$ becomes $\omega_{e}$. In the SFO control system, the stator flux vector is aligned with the $d$-axis, which means

$$
\psi_{s}=\psi_{s d}, \quad \psi_{s q}=0
$$

Taking (4) into account, (2) becomes

$$
0=\frac{1}{T_{r}} \boldsymbol{\psi}_{r}-\frac{L_{m}}{T_{r}} \boldsymbol{\psi}_{r}+s \boldsymbol{\psi}_{r}+j\left(\omega-\omega_{r}\right) \boldsymbol{\psi}_{r}
$$

where $s$ is the Laplace operator $(=\mathrm{d} / \mathrm{d} t)$.

Taking (3) and (4) into account, (15) can be modified as

$$
\left(1+s T_{r}\right) \boldsymbol{\psi}_{s}=\left(1-s \sigma T_{r}\right) L_{s} \mathbf{i}_{s}-j \omega_{+} s T_{r}\left(\boldsymbol{\psi}_{s}-\sigma L_{s} \mathbf{i}_{s}\right) .
$$

Rewriting (16) in the $d, q$ reference frame and considering (14), (16) becomes

$$
\begin{gathered}
\left(1+s T_{r}\right) \boldsymbol{\psi}_{r}=\left(1+s \sigma T_{r}\right) L_{s} i_{s d}-\omega_{s} \sigma T_{r} L_{s} i_{s q} \\
\omega_{s} T_{r}\left(\boldsymbol{\psi}_{s}-\sigma L_{s} i_{s d}\right)=L_{s}\left(1+s \sigma T_{r}\right) i_{s q}
\end{gathered}
$$

Equations (17) and (18) indicate that the stator flux $\psi_{s d}$ is a function of both the $i_{s d}$ and $i_{s q}$ currents. In other words, there is a coupling effect. Consider the decoupler shown in Fig. 1 where the decoupling signal $i_{d e c}$ is added to the stator flux control loop to generate the $d$-axis stator current reference $i_{s d} \mid$. This decoupling signal can be calculated using the following equation [14]

$$
i_{d e c}=\frac{\sigma L_{s} i_{s q}^{2}}{\psi_{s}-\sigma L_{s} i_{s d}} .
$$

Hence, the stator flux in the SFO control system is controlled by the $d$-axis stator current in the $d, q$ reference frame.

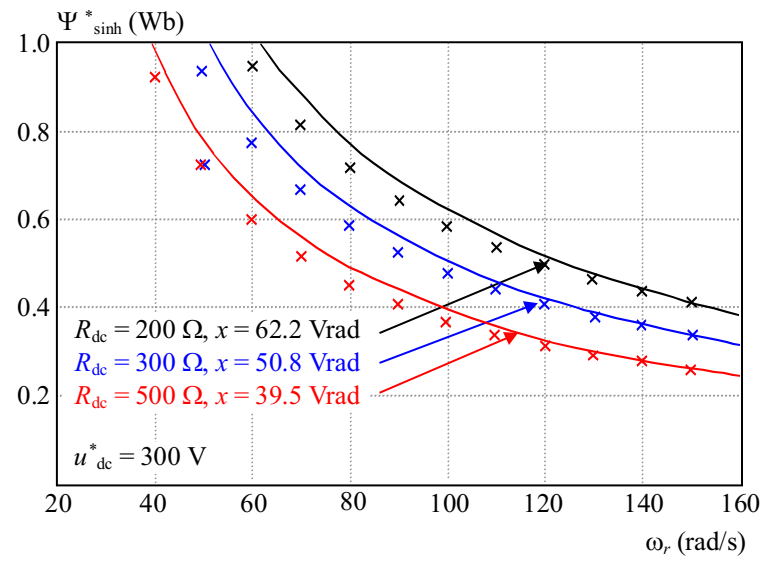

Fig. 4. Minimum stator flux reference versus rotor speed obtained at fixed dc-link voltage reference and varying load

\section{DETERMINATION OF STATOR FLUX REFERENCE}

The goal of the control system for an induction generator is to maintain a constant stator voltage. In the steady state, from (1) and by neglecting $R_{s}$, the no-load stator voltage $\left(\omega_{s}=0\right)$ can be written as $[3,11]$

$$
E=\omega_{r} \boldsymbol{\psi}_{s}
$$

This means that the stator voltage can be controlled indirectly by programming the machine stator flux. To keep the voltage on the terminals constant, the product of the speed and the flux should remain constant. As proposed in [3] and [11], the following equation can be used to calculate the reference stator flux

$$
\boldsymbol{\psi}^{*}=\frac{\omega_{r \min }}{\omega_{r}} \boldsymbol{\psi}_{s \max }=\frac{x}{\omega_{r}} .
$$

However, (21) ensures stable and reliable operating regimes only for limited range of dc-load and dc-link voltage references. In applications, the magnetic saturation of the main magnetizing circuit (the maximum stator flux linkage) and the mechanical rating of a generator (the maximum rotor speed) are the key factors that limit stability. In order to ensure a constant stator voltage, the maximum rotor speed should correspond to the minimum stator flux linkage (the point $\left.\left(\omega_{\max }, \psi_{\text {smin }}\right)\right)$. Analogously, the maximum stator flux linkage should correspond to the minimum rotor speed (the point $\left.\left(\omega_{\min }, \psi_{\text {smax }}\right)\right)$. However, both points depend not only on the limits previously mentioned, but also on the dc-link voltage reference and load. Therefore, we propose a modification of (21) as follows

$$
\psi_{s}^{*}=\frac{x\left(u_{d c}^{*}, R_{d c}\right.}{\omega_{r}}
$$

In order to establish how the magnetization factor $\mathrm{x}$ depends on the dc-link voltage reference and load, we used a simulation program similar to the program shown in Fig. 2. The only difference is that the stator flux reference is not determined by a neural network, but manually, 


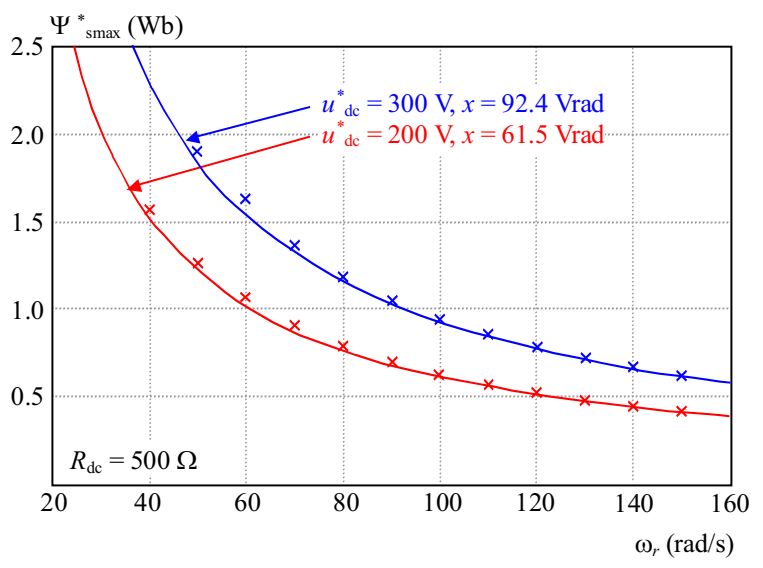

Fig. 5. Maximum stator flux reference versus rotor speed obtained at fixed load and for varying dc-link voltage references

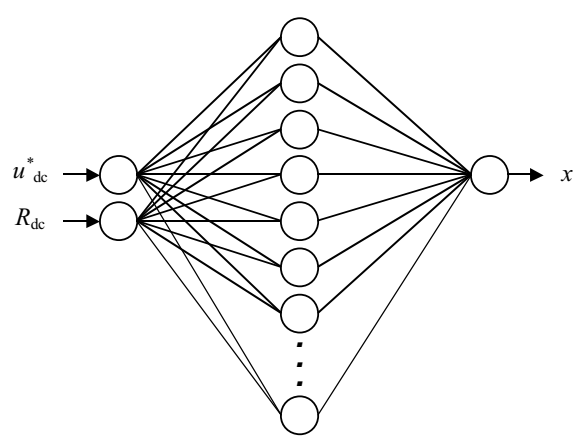

Fig. 7. Topology of the 2-40-1 ANN for magnetization factor determination

as will be described in the following text. Load ranges between $100 \Omega$ and $700 \Omega$ and dc-link reference ranges between $150 \mathrm{~V}$ and $450 \mathrm{~V}$ were studied. The maximum rotor speed is fixed at $150 \mathrm{rad} / \mathrm{s}$. By using the simulation program, the minimum and maximum stator flux references were determined by trial and error over the dc-link voltage and load range (these points are denoted by the asterisks in Figs. 3-5). Note that the stator flux reference is set manually for this purpose, not by the neural network.

Figure 3 shows the dependence of the minimum stator flux reference on the rotor speed, obtained for the load $R_{d c}=500 \Omega$ and varying dc link voltage references. In addition, Fig. 4 shows the dependence of the minimum stator flux reference on the rotor speed, obtained for a dc link voltage of $u_{d c}^{*}=300 \mathrm{~V}$ and varying dc loads. The solid lines in Figs. 3, 4 approximate the curves outlined by the asterisks. However, none of the asterisks lie above the corresponding solid line. This ensures minimum system stability. Each curve shown in Figs. 3 and 4 is described by (21) with a different factor $x\left(x_{\min }\right)$.

We also obtained the dependence of the maximum stator flux reference on the rotor speed for variable dc-link voltages and loads, in a manner similar to that described for the minimum stator flux reference. Figure 5 shows the dependence of the maximum stator flux reference on

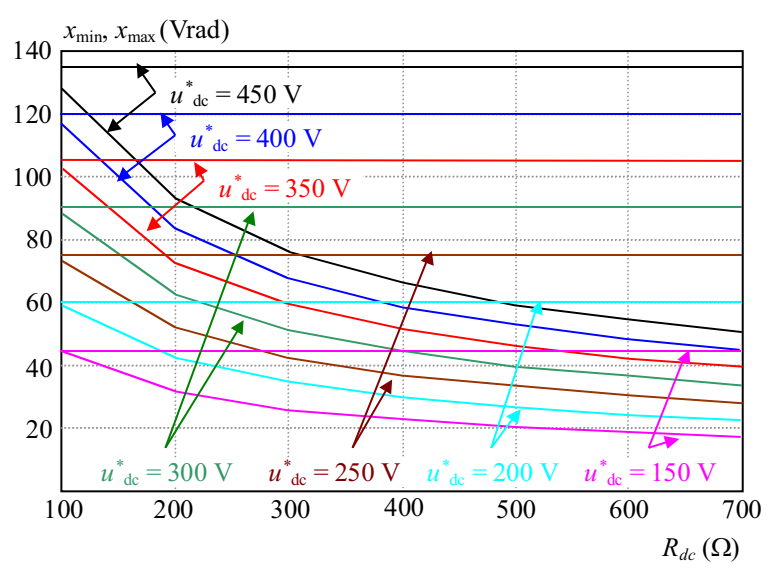

Fig. 6. Minimum and maximum magnetization factors, as functions of dc-link voltage reference and load

rotor speed, obtained for the load $R_{d c}=500 \Omega$ and for varying dc-link voltage references. The solid lines in Fig. 5 approximate the curve outlined by the asterisks, but this time none of the asterisks lie below the related solid line. The factor $x\left(x_{\max }\right)$ is specified for each curve.

We noticed that the maximum stator flux reference does not depend significantly on the load.

Figure 6 shows overall results obtained for the minimum and the maximum stator flux reference. The curves $x_{\min }\left(u_{d c}^{*}, R_{d c}\right)$ and $x_{\max }\left(u_{d c}^{*}, R_{d c}\right)$ determine the boundaries of system stability for particular dc-link voltages and loads.

In addition, we calculated the average factor $x\left(x_{\mathrm{avg}}\right)$ as the arithmetic mean of the minimum and maximum factors $x$ obtained for each dc-link voltage reference and load. In simulations, this factor $x$ is obtained for a particular dc-link voltage reference and load using a neural network as shown in Fig. 2 and as described in the following section.

\subsection{Non-linear Mapping of the Magnetization Factor based on a Neural Network}

The most commonly used ANNs are feedforward multilayer networks, where no information is fed back during application. Supervised learning methods are typically used, where the neural network is trained to learn the input/output patterns presented to it [16].

In this paper, we utilize a three-layer neural network, where the input pat tern includes a set of dc link voltage references and loads. The output pattern includes a set of magnetization factors (the first ANN gives $x_{\min }$, the second ANN gives $x_{\max }$ and the third ANN gives $\left.x_{\text {avg }}\right)$. We used trial and error to find a suitable neural network architecture. The number of neurons comprising each neural network is 2, 40 and 1 , in the first, second and third layers, respectively (the structure is $2-40-1$, as shown in Fig. 7). The activation functions in the first layer and in the hidden layer are tan-sigmoid functions, and the activation function in the output layer is linear. Each neuron of the ANN is illustrated in Fig. 7 by a small circle. 

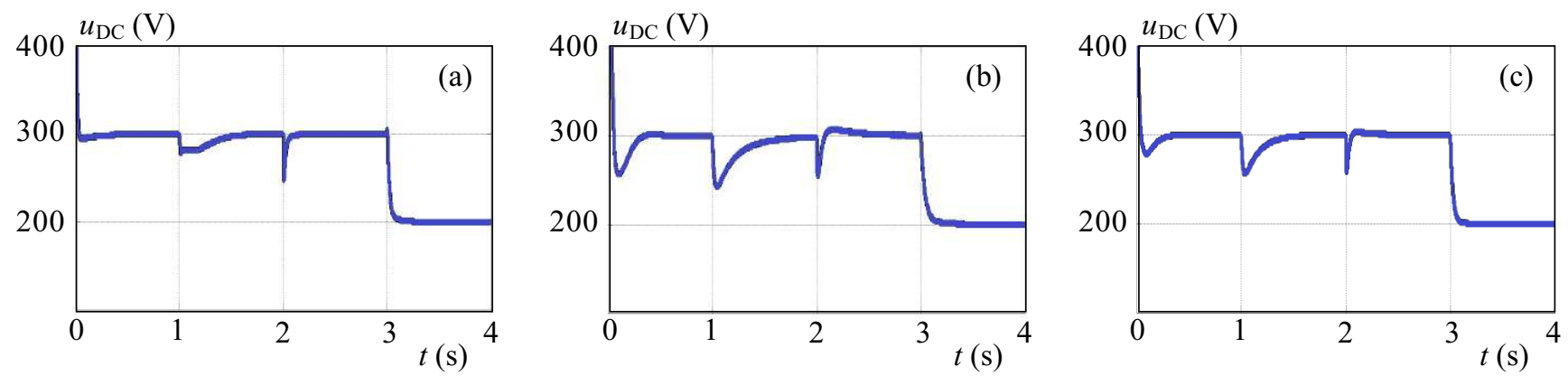

Fig. 8. DC-link voltage obtained at the maximum (a), minimum (b) and average (c) magnetization factor
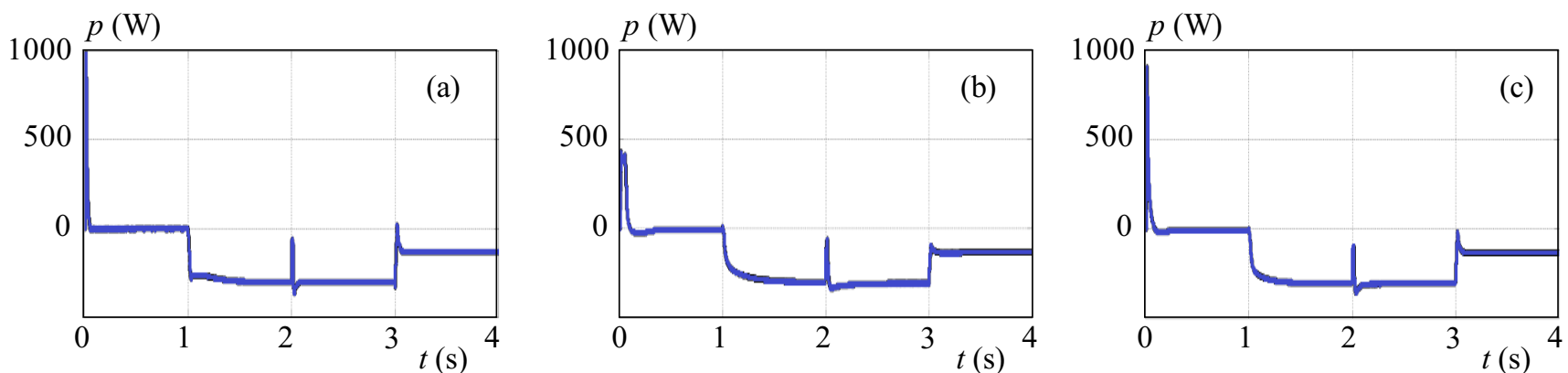

Fig. 9. Averaged dc-link output power obtained at maximum (a), minimum (b) and average (c) magnetization factors
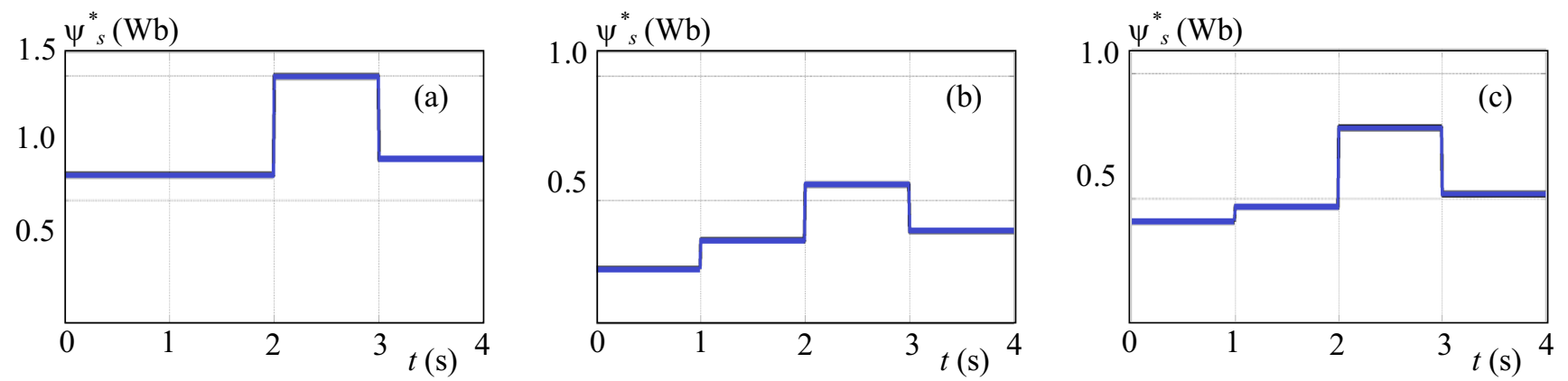

Fig. 10. Stator flux reference obtained at maximum (a), minimum (b) and average (c) magnetization factors

Table 1. Efficiency for dc-link voltage reference $300 \mathrm{~V}$, load $500 \Omega$ and variable rotor speed

\begin{tabular}{ccccccc}
\hline$\omega(\mathrm{rad} / \mathrm{s})$ & 125 & 112.5 & 100 & 87.5 & 75 & 62.5 \\
$\eta\left(x_{\max }\right)$ & 0.882 & 0.862 & 0.836 & 0.8 & 0.710 & 0.472 \\
$\eta\left(x_{\min }\right)$ & 0.729 & 0.733 & 0.734 & 0.729 & 0.718 & 0.696 \\
$\eta\left(x_{\mathrm{avg}}\right)$ & 0.901 & 0.890 & 0.874 & 0.852 & 0.82 & 0.771 \\
\hline
\end{tabular}

Table 2. Efficiency for dc-link voltage reference $300 \mathrm{~V}$, rotor speed $125 \mathrm{rad} / \mathrm{s}$ and variable load

\begin{tabular}{ccccccc}
\hline$R_{d c}(\Omega)$ & 600 & 500 & 400 & 300 & 200 & 100 \\
$\eta\left(x_{\max }\right)$ & 0.873 & 0.882 & 0.888 & 0.888 & 0.868 & 0.733 \\
$\eta\left(x_{\min }\right)$ & 0.732 & 0.729 & 0.718 & 0.709 & 0.704 & 0.702 \\
$\eta\left(x_{\mathrm{avg}}\right)$ & 0.910 & 0.901 & 0.888 & 0.869 & 0.832 & 0.719 \\
\hline
\end{tabular}

Table 3. Efficiency for load $500 \Omega$, rotor speed $125 \mathrm{rad} / \mathrm{s}$ and variable dc-link voltage reference

\begin{tabular}{ccccccc}
\hline$u_{d c}^{*}(\mathrm{~V})$ & 350 & 300 & 250 & 200 & 150 & 130 \\
$\eta\left(x_{\max }\right)$ & 0.882 & 0.882 & 0.882 & 0.883 & 0.884 & 0.885 \\
$\eta\left(x_{\min }\right)$ & 0.730 & 0.729 & 0.727 & 0.725 & 0.723 & 0.718 \\
$\eta\left(x_{\mathrm{avg}}\right)$ & 0.901 & 0.901 & 0.901 & 0.901 & 0.899 & 0.898 \\
\hline
\end{tabular}

The neural network shown in Fig. 7 is able to map input/output patterns with a total network error equal to $10^{-4}$.

\section{SIMULATION RESULTS}

In this section, the $\mathrm{SFO}$ control system is evaluated both in terms of efficiency and in terms of performance during transients, over a wide range of both dc-link voltage references and loads.

In order to establish how different magnetization factors determine transients of the control system, a partic- 


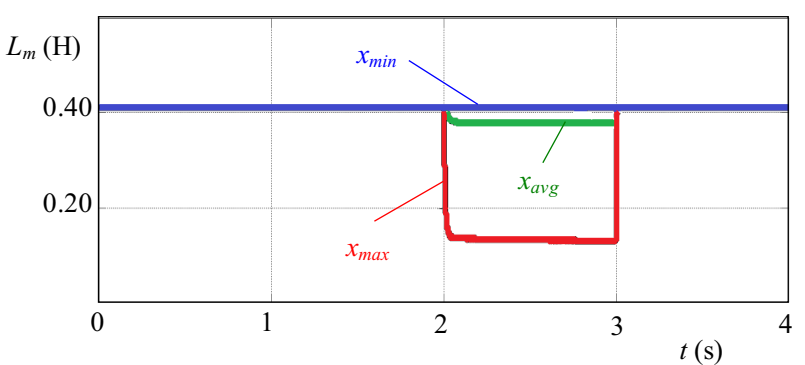

Fig. 11. Mutual inductance obtained at maximum, minimum and average magnetization factors

ular operating regime was selected as follows. The induction generator starts at a speed of $150 \mathrm{rad} / \mathrm{s}$ with no load, and the dc voltage reference is equal to $300 \mathrm{~V}$. At time $1 \mathrm{~s}$, the induction generator is rapidly loaded to $300 \Omega$. At time $2 \mathrm{~s}$, the rotor speed is rapidly changed to $80 \mathrm{rad} / \mathrm{s}$. Finally, at time $3 \mathrm{~s}$, the dc voltage reference is rapidly changed to $200 \mathrm{~V}$. Figure 8 shows the dc-link voltage obtained using minimum, maximum and average magnetization factors. Figures 9 and 10 show the average dc-link power and the stator flux reference obtained using these same magnetization factors. The dc-link power is averaged (filtered) over a $20 \mathrm{~ms}$ period.

Faithful tracing of the dc-link voltage and average output power can be seen in Figs. 8 and 9, respectively. Figure 10 shows that the magnetization factor is critical for determining the stator flux reference. For example, the highest magnetization factor results in the highest stator flux reference (Fig. 10a) and the minimum magnetization factor results in the lowest stator flux reference (Fig. 10b).

Figure 11 shows the mutual inductance as a function of time for the three magnetization factors. Only the highest magnetization factor causes the saturation of the mutual inductance. When the magnetization factor is equal to its minimum or average value, the mutual inductance remains unsaturated.

By analyzing the transients of the SFO control system, we recommend use of the average magnetization factor, because this factor, as opposed to the minimum or maximum magnetization factor, ensures that the system remains in its range of stability.

In order to illustrate the efficiency of the SFO control system for the aforementioned magnetization factors, the results obtained from the simulations are summarized in Tables 1, 2 and 3 as follows:

Table 1 shows the induction generator efficiency for fixed parameters $u_{d c}^{*}=300 \mathrm{~V}$ and $R_{d c}=500 \Omega$. The rotor speed varies.

Table 2 shows the induction generator efficiency for fixed parameters $u_{d c}^{*}=300 \mathrm{~V}$ and $\omega=125 \mathrm{rad} / \mathrm{s}$. The load varies.

Table 3 shows the induction generator efficiency for fixed parameters $R_{d c}=500 \Omega$ and $\omega=125 \mathrm{rad} / \mathrm{s}$. The dclink voltage reference varies.
From Tables 1, 2 and 3, we can make the following conclusions:

1) The minimum magnetization factor almost always results in the minimum efficiency, except over a low speed range when the minimum efficiency is obtained with the maximum magnetization factor (Table 1, last column).

2) The maximum efficiency is achieved by using either the average or the maximum magnetization factor.

3) When the efficiency obtained using the maximum magnetization factor is higher than that obtained for the average magnetization factor, the efficiency difference is less than $2 \%$.

4) When the efficiency obtained using the average magnetization factor is higher than the efficiency obtained using the maximum magnetization factor, the efficiency improvement can be higher than $60 \%$ (Table 1, last column).

Importantly, in this paper we consider only the winding (conductor) fundamental losses of the induction generator. In low power induction machines, where the conductor losses dominate, this assumption is valid. For a more accurate efficiency calculation, magnetic losses, stray losses and mechanical losses should also be included.

\section{CONCLUSION}

A SFO control system for an induction generator is greatly influenced by the stator flux reference. In this paper, we introduce a new algorithm in which the product of the stator flux reference and the rotor speed is kept constant for certain dc-load and dc-link voltage references. The relationship between the stator flux reference and the rotor speed is determined by the magnetization factor. The stability of the system is limited to a range defined by the minimum and maximum magnetization factors.

A feedforward artificial neural network is able to map the dependence of the stator flux reference on the dc load and the dc voltage reference, in cases when the minimum, maximum or average magnetization factors are applied.

From the viewpoint of stability and efficiency, extensive computer simulations show that the best choice of magnetization factor is its average value. With this value, system stability is ensured and system efficiency is most often highest.

In future work, the control system will be upgraded with stator resistance identification.

\section{Appendix (induction machine parameters)}

$P_{n}=1.5 \mathrm{~kW}, U_{n}=380 \mathrm{~V}, P=4, \mathrm{Y}, I_{n}=3.81 \mathrm{~A}$, $n_{n}=1391 \mathrm{r} / \mathrm{min}, L_{m}=0.3269 \mathrm{H}, L_{s l}=0.01823 \mathrm{H}$, $L_{r l}=0.02185 \mathrm{H}, R_{s}=4.5633 \Omega, R_{r}=3.866 \Omega$ (at $\left.20{ }^{\circ} \mathrm{C}\right), t_{n}=10.5 \mathrm{Nm}, J=0.0071 \mathrm{kgm}^{2}, \psi_{s n}=0.929 \mathrm{~Wb}$. 


\section{REFERENCES}

[1] WAGNER, C.: Self-Excitation of Induction Motors, Transactions of the American Institute of Electrical Engineers 58 (1939), 47-51, DOI: 10.1109/T-AIEE.1939.5057921.

[2] BASSET, E. D.-POTTER, F. M. : Capacitive Excitation for Induction Generators, Transactions of the American Institute of Electrical Engineers 54 (1935), 540-545.

[3] SIMOES, M. G.-CHAKRABORTY, S.-WOOD, R. : Induction Generators for Small Wind Energy Systems, IEEE Power Electronics Society Newsletter 18(3) (2006), 19-23.

[4] SIMOES, M. G.-FARRET, F. A. : Renewable Energy Systems: Design and Analysis with Induction Generators, CRC Press, 2004.

[5] SINGH, G. K.: Self-Excited Induction Generator Research a Survey, Electric Power Systems Research 69 (2004), 107-114, DOI: 10.1016/j.epsr.2003.08.004.

[6] BHADRA, S. N.-RATNAM, K. V.-MAnJunAth, A.: Study of Voltage Build up in a Self-Excited, Variable Speed Induction Generator / Static Inverter System with DC Side Capacitor, International Conference on Power Electronics, Drives and Energy Systems, New Delhi, India, 1996, pp. 964-970.

[7] LIN, F.-HUANG, P.-WANG, C.-TENG, L. : An Induction Generator System Using Fuzzy Modeling and Recurrent Fuzzy Neural Network, IEEE Transactions on Power Electronics 2(1) (2007), 260-271, DOI: 10.1109/TPEL.2006.886653.

[8] LIAO, Y. W.-LEVI, E.: Modelling and Simulation of a Stand-Alone Induction Generator with Rotor Flux Oriented Control, Electric Power Systems Research 46 (1998), 141-152, DOI: 10.1016/S0378-7796(98)00039-X.

[9] WEE, S.-D.-SHIN, M.-H.-HYUN, D.-S.: Stator-Flux-Oriented Control of Induction Motor Considering Iron Loss, IEEE Transactions on Industrial Electronics 48(3) (2001), 602-608, DOI: $10.1109 / 41.925587$.

[10] LEIDHOLD, R.-GARCIA, G.-VALLA, M. I.paper FieldOriented Controlled Induction Generator with Loss Minimization: IEEE Transactions on Industrial Electronics 49(1) (2002), 147-156, DOI: 10.1109/TEC.2002.801994.

[11] SEYOUM, D.: The Dynamic Analysis and Control of a Self-Excited Induction Generator Driven by a Wind Turbine, PhD Thesis, The University of New South Wales, 2003.
[12] NOVOTnY, D. W.-LIPO, T. A. : Vector Control and Dynamics of AC Drives, Oxford University Press, New York, 1996.

[13] VUKADINOVIC, D.-SMAJO, M.-KULISIC, Lj.: Rotor Resistance Identification in an IRFO System of a Saturated Induction Motor, International Journal of Robotics and Automation 24(1) (2009), 38-47, DOI: 10.2316/Journal.206.2009.1.206-3167.

14] VUKADINOVIC, D.-SMAJO, M. : Analysis of Magnetic Saturation in Induction Motor Drives, International Review of Electrical Engineering (IREE) 3(2) (2008), 326-336.

15] BOSE, B. K. : Modern Power Electronics and AC Drives, Prentice Hall PTR, 2002.

[16] NGUYEN, H. T.-PRASAD, N. R.-WALKER, C. L.-WALKER, E. A. : A First Course in Fuzzy and Neural Control, CRC Press Company, Boca Raton, 2003.

Received 9 May 2010

Dinko Vukadinović was born in Banja Luka, Bosnia and Herzegovina, in 1973. He received the B.E. degree from the University of Split, the M.E. degree from the University of Zagreb and the Ph.D. degree from the University of Split, Croatia, in 1997, 2002 and 2005, respectively, all in electrical engineering. He became a junior researcher in the University of Split, Faculty of Electrical Engineering, Mechanical Engineering and Naval Architecture, Department of Electric Power Engineering, in 1998. In 2006, he became an Assistant Professor at the University of Split. He is an Associate Editor of the Journal of Engineering, Computing \& Architecture and Journal of Computer Science, Informatics and Electrical Engineering. His research interests include induction machine control systems, power electronics, digital signal processors and artificial intelligence. He has published a number of papers in major scientific journals.

Mateo Bašić was born in Split, Croatia, in 1982. He received the B.E. degree from the University of Split, Croatia, in 2006, in electrical engineering. He became an assistant at the University of Split, Faculty of Electrical Engineering, Mechanical Engineering and Naval Architecture, Department of Electric Power Engineering, in 2008. His research interests include induction machine control systems and power electronics. 